\title{
ADHERENCE TO TREATMENT AMONG TYPE 2 DIABETES PATIENTS ATTENDING TERTIARY CARE HOSPITAL IN AGARTALA CITY- A CROSS-SECTIONAL STUDY
}

\author{
Shyamal Roy ${ }^{1}$, Taranga Reang ${ }^{2}$ \\ ${ }^{1}$ Associate Professor, Department of Medicine, Agartala Government Medical College and GB Pant Hospital, Agartala, Tripura. \\ ${ }^{2}$ Assistant Professor, Department of Community Medicine, Agartala Government Medical College and GB Pant Hospital, Agartala, \\ Tripura.
}

\section{BACKGROUND}

ABSTRACT

Poor adherence or non-adherence is a great problem in the control of diabetes mellitus type 2. Despite the advances in the treatment of diabetes mellitus type 2 over the years, diabetes remains as a burden on the individuals living with the condition, their families, societies and overall health care delivery system.

The objective of this study is to assess the proportion of diabetic patients' adherence to treatment and identify important sociodemographic factors for non-adherence.

\section{MATERIALS AND METHODS}

A cross-sectional study was conducted among 100 type 2 diabetic patients attending Outpatient Department (OPD) of a tertiary care hospital of Agartala city located in the North Eastern part of India. The systematic random sampling technique was used for selection of the study subjects. Adherence was measured using the standardised and widely used four-item Morisky Medication Adherence Scale (MMAS-4).

\section{RESULTS}

The overall mean (SD) age was 53.17 ( \pm 11.543 ) years. The proportion of females/ males with type 2 DM was found to be $58 \%$ and $42 \%$ respectively. The adherence to treatment among the DM2 patients was $44.0 \%$ compared to non-adherence $56.0 \%$. The sex, age, literacy, occupation, income and caste did not show any significant association with treatment adherence. Among Hindu, almost $40.4 \%$ adherence was observed $(\mathrm{p}=0.017)$.

\section{CONCLUSION}

The overall adherence was $44.0 \%$, suggesting poor adherence to treatment among the diabetes patients. Females were more adherent compared to males ( $p>0.05$ ). The level of education was directly proportional to the treatment adherence ( $p>0.05)$. No significant relationships were observed between sex, literacy, income, occupation and caste with treatment adherence.

\section{KEYWORDS}

Adherence to Treatment, Type 2 Diabetes Mellitus, Outpatient Department, Tertiary Care Hospital.

HOW TO CITE THIS ARTICLE: Roy S, Reang T. Adherence to treatment among type 2 diabetes patients attending tertiary care hospital in Agartala city- a cross-sectional study. J. Evolution Med. Dent. Sci. 2018;7(10):1223-1227, DOI: $10.14260 /$ jemds/2018/279

\section{BACKGROUND}

The prevalence of diabetes mellitus (DM) is rising worldwide and is more in the developing countries, which unfortunately are already suffering from communicable diseases.(1) The incidence of diabetes mellitus has continued to increase globally with the resulting burden resting more heavily on tropical, developing countries. (2,3) According to an ICMR study the prevalence of Diabetes Mellitus Type 2 (DM2) in Tripura is $9.0 \%$.(4) Type $2 \mathrm{DM}$, which is more common, is increasingly being recognised in relatively young persons due to high prevalence of environmental and genetic risk factors. (3) People living with type $2 \mathrm{DM}$ are more vulnerable to varied forms of both short and long-term complications, which often lead to their premature death. It is predicted that prevalence of diabetes mellitus in adults will increase in the

'Financial or Other Competing Interest': None.

Submission 19-02-2018, Peer Review 20-02-2018,

Acceptance 23-02-2018, Published 05-03-2018.

Corresponding Author:

Dr. Taranga Reang,

Assistant Professor, Department of Community Medicine, Agartala Government Medical College \& GB Pant Hospital,

Agartala, Tripura.

E-mail: tarangareang@gmail.com

DOI: $10.14260 /$ jemds $/ 2018 / 279$

\section{(c) $(1) \ominus$}

next two decades and much of the increase will occur in developing countries where the majority of patients are aged between 45 and $64 .(5,6)$ It is estimated that over $70 \%$ of people with diabetes will reside in developing countries by the year 2030.(7) Although hyperglycaemia often presents with few outward symptoms, tight control of blood glucose is needed to prevent many of the short and long-term complications of type 2 diabetes. A blood glucose control goal requires active patient participation in order to master a complex array of self-management skills. These include modifying dietary choices, implementing exercise regimes, monitoring blood glucose and adhering to often complex medication regimens. $(8,9)$ Adherence means the extent to which a person's behaviour taking medication and/or executing lifestyle changes, corresponds with agreed recommendations from a health care provider.(10) One way in which patients will be better able to manage their illnesses is by adhering to their medication regimens. Many patients, especially patients with chronic illness, experience difficulties in following treatment recommendations. Adherence to longterm therapy for chronic illnesses averages only $50.0 \%$.(10) As $^{(1)}$ a result of poor adherence, patients do not receive optimal benefit from their drug therapy. Suboptimal treatment can lead to increased use of health care services, reduction in patient's quality of life and increased health care costs. $(10,11,12)$ 
The reports of World Health Organisation have emphasised that "increasing the effectiveness of adherence interventions may have a far greater impact on the health of the population than any improvement in specific medical treatments."(10) Medication adherence is a major universal factor influencing patient's health outcomes, particularly in chronic diseases such as diabetes. Non-adherence/poor adherence to antidiabetes medication can cause treatment failure leading to diabetes-related complications such as retinopathy, neuropathy, nephropathy, reduced quality of life etc. The factors of medication non-adherence/poor adherence should be addressed properly.(10) The aim of this study was to assess medication adherence/non-adherence among type 2 diabetes patients and to identify probable factors associated with nonadherence at tertiary care hospital in Agartala city located in the North Eastern part of India. It can help create awareness among diabetes patients and prevent disability. It may be helpful to administrators for better planning and implementation in future through NPCDCS. The objectives were- (1) To assess the proportion of type 2 Diabetic patients' adherence to treatment; (2) To identify the associated socio-demographic factors for non-adherence to treatment.

\section{MATERIALS AND METHODS}

A cross-sectional study was conducted among patients attending Outpatient Department (OPD) of a tertiary care hospital of Agartala city, located in the North Eastern part of India. Agartala city is the second largest city in the North East India next to Guwahati. The overall population of the state is $3,671,032$ with $1,871,867$ males and $1,799,165$ females. The population density in Tripura is 350 per square $\mathrm{km}$ (Census India 2011).(13) Tripura is bordered by the country of Bangladesh to the west, north and south; and the Indian states of Assam to the north east; and Mizoram to the east. The overall area of the Agartala Municipal Corporation is 76.504 square $\mathrm{km}$ and the population was $4,38,408$ after the completion of the restructuring of the Agartala city in 2013. The percentage of literacy according to 2011 census was 93.88, higher than the national literacy rate (Census India 2011).(13) Diabetic clinics is running in the hospital every day and records are well maintained in the OPD register. The sample size (n) 100 was calculated using formula for single proportion $\mathrm{Z} 1-\alpha / 2^{2} \mathrm{p}(1-\mathrm{p}) / \mathrm{d}^{2}$. The ' $\mathrm{p}$ ' was assumed 0.5 with $95 \%$ confidence interval and 5\% level of significance. The precision (d) was taken as 0.10 in the present study. The lists of DM2 patients $(\mathrm{N})$ in the diabetes clinic of the hospital were available. The systematic random sampling technique was used for selection of the study subjects. Sampling interval (K) was determined by dividing the number of units in the population by the desired sample size. Thus, the sampling interval was $(K=N / n)$ calculated. Simple random sampling (lottery method) was applied for the first patients to get the starting point. Thereafter, depending on sampling interval patients coming to the clinic were enrolled in the study until the required sample size was achieved. The diabetes patients who did not refuse to participate were included in the study. If the previously enrolled patients were selected for the consecutive times were not eligible for inclusion for the second time. The seriously ill patients requiring admission or dialysis were excluded. Data were collected using structured interview schedule.

The questionnaire for the interview has had two sections: Socio-demographic variables and adherence questions (4-point response, MMAS). Adherence was measured using the standardised and widely used four-item Morisky Medication Adherence Scale (MMAS-4). Those patients who scored $<3$ from the 4-point response Morisky Medication Adherence Scale (MMAS) was considered adherent, otherwise non-adherent.(10) The questionnaire was prepared in English and translated into local language, while doing interview by the researcher. The participants were requested to participate in the study voluntarily. The informed written consent was obtained from the participants before conducting the study. The information so collected was kept confidential and anonymous. The permission from IEC was obtained before conducting the study. The data were collected from October to December 30, 2017.

\section{DataAnalysis}

Data were checked, sorted, categorised and coded. After coding, the data were entered into the computer to make it ready for processing and analysis. It was analysed by using the SPSS version 15.0 software. Descriptive statistics were used to calculate the means, standard deviations and frequencies of the study variables. For inferential statistics Chi-square $\left(\mathrm{X}^{2}\right)$ tests were used to determine the association between dependent and independent variables. P-values $<0.05$ were considered as statistically significant. For analysis of adherence, a cut-off value of MMAS score $<3$ and $\geq 3$ was used for labelling patients as adherent or non-adherent respectively. The MMAS consists of four items with a scoring scheme of "Yes" $=0$ and "No" $=1$. The items were summed to give a range of scores from 0 to 4 . Morisky Medication Adherence Scale (MMAS), a 4-item questionnaire with a high reliability and validity, which has been particularly useful in chronic conditions such as diabetes was used.(10)

\section{RESULTS}

There were $42.0 \%$ male and $58.0 \%$ female among the diabetes patients. The overall mean (SD) age was 53.17 $( \pm 11.543)$ years. The mean (SD) age of male and female were $55.17( \pm 10.219)$ and $51.72( \pm 12.297)$ respectively. More than half $(54.0 \%)$ of the DM2 patients were $>50$ years' age group Almost 99.0\% were literate and 50.0\% homemaker and $32.0 \%$ family income ranges from Rs. 5001/- to $10,000 /-$ only. Majority were Hindu (94.0\%) and General (84.0\%) caste belonged to nuclear family $(60.0 \%)$, (Table 1). The adherence to treatment among the patients was $44.0 \%$ compared to non-adherence $56.0 \%$ (Table 2). The sex, age, literacy, occupation, income and caste did not show any significant relationship with treatment adherence. Among Hindus, higher proportion of non-adherence was observed $(p<0.05)$ compared to other castes (Table 3). The factors that seems to be responsible for non-adherence were male sex $(\mathrm{M}=57.1 \%$ vs. $\mathrm{F}=55.2 \%$ ), younger age group (30 - $40 \mathrm{yrs}$.) $72.7 \%$, literacy (under matric) $72.2 \%$, higher income (Rs. 15,000/- to 20,000/-) 91.7\% group, Hindus 59.6\% and STs 
$75.0 \%$ were more non-adherent compared to other categories ( $\mathrm{p}>0.05)$ (Table 3$)$.

\begin{tabular}{|c|c|c|}
\hline Variables & $\begin{array}{c}\text { Number } \\
(\mathrm{N})\end{array}$ & $\begin{array}{c}\text { Percentage } \\
(\%)\end{array}$ \\
\hline \multicolumn{3}{|c|}{ Age Group (Years) } \\
\hline 20-30 yrs. & 3 & 3.0 \\
\hline $30-40$ yrs. & 11 & 11.0 \\
\hline $40-50$ yrs. & 32 & 32.0 \\
\hline$>50$ yrs. & 54 & 54.0 \\
\hline \multicolumn{3}{|c|}{ Sex } \\
\hline Male & 42 & 42.0 \\
\hline Female & 58 & 58.0 \\
\hline \multicolumn{3}{|c|}{ Literacy Status } \\
\hline Illiterate & 1 & 1.0 \\
\hline Under Matric & 36 & 36.0 \\
\hline Higher Secondary & 24 & 24.0 \\
\hline Graduate and Above & 39 & 39.0 \\
\hline \multicolumn{3}{|c|}{ Occupation } \\
\hline Govt. Employee & 19 & 19.0 \\
\hline Unemployed & 31 & 31.0 \\
\hline Homemaker & 50 & 50.0 \\
\hline \multicolumn{3}{|c|}{ Family Income (Rs.) } \\
\hline$\leq 5000$ & 22 & 22.0 \\
\hline $5000-10000$ & 32 & 32.0 \\
\hline $10000-15000$ & 8 & 8.0 \\
\hline $15000-20000$ & 12 & 12.0 \\
\hline$>20000$ & 26 & 26.0 \\
\hline \multicolumn{3}{|c|}{ Caste } \\
\hline Gen & 84 & 84.0 \\
\hline SC & 12 & 12.0 \\
\hline ST & 4 & 4.0 \\
\hline \multicolumn{3}{|c|}{ Religion } \\
\hline Hindu & 94 & 94.0 \\
\hline Muslim & 5 & 5.0 \\
\hline Christian & 1 & 1.0 \\
\hline \multicolumn{3}{|c|}{ Type of Family } \\
\hline Nuclear & 60 & 60.0 \\
\hline Joint & 40 & 40.0 \\
\hline \multicolumn{3}{|c|}{ Residence } \\
\hline Urban & 54 & 54.0 \\
\hline Rural & 46 & 46.0 \\
\hline \multicolumn{3}{|c|}{$\begin{array}{l}\text { Table 1. Socio-Demographic Profile of } \\
\text { Type } 2 \text { Diabetes Patients }\end{array}$} \\
\hline
\end{tabular}

\begin{tabular}{|c|c|c|}
\hline MMA Scale & $\begin{array}{l}\text { Yes, N } \\
(\%)\end{array}$ & $\begin{array}{l}\text { No, } N \\
(\%)\end{array}$ \\
\hline Do you ever forget to take medicine? & $\begin{array}{c}46 \\
(46.0)\end{array}$ & $54(54.0)$ \\
\hline $\begin{array}{l}\text { Do you ever have problems } \\
\text { remembering to take your medication? }\end{array}$ & $\begin{array}{c}35 \\
(35.0) \\
\end{array}$ & $65(65.0)$ \\
\hline $\begin{array}{c}\text { When you feel better, do you sometimes } \\
\text { stop taking your medicine? }\end{array}$ & $21(21.0)$ & $79(79.0)$ \\
\hline $\begin{array}{c}\text { Sometimes if you feel worse when you } \\
\text { take your medicine, do you stop taking } \\
\text { it? }\end{array}$ & $8(8.0)$ & $92(92.0)$ \\
\hline \multicolumn{3}{|l|}{ MMA Score } \\
\hline & \multicolumn{2}{|c|}{ Number Percentage } \\
\hline$<3$ score & 44 & 44.0 \\
\hline$\geq 3$ & 56 & 56.0 \\
\hline $\begin{array}{r}\text { Table 2. The Distributio } \\
\text { according to } M M A\end{array}$ & $\begin{array}{l}\text { DM Pat } \\
\text { esponse }\end{array}$ & ents \\
\hline
\end{tabular}

\begin{tabular}{|c|c|c|c|}
\hline \multirow[b]{2}{*}{ Variables } & \multicolumn{2}{|c|}{$\begin{array}{l}\text { Adherence Scale } \\
\text { (MMAS 4 Items) }\end{array}$} & \multirow[b]{2}{*}{ P-value } \\
\hline & $\begin{array}{c}\text { Adherence } \\
(<3)\end{array}$ & $\begin{array}{c}\text { Non- } \\
\text { Adherence } \\
(\geq 3)\end{array}$ & \\
\hline \multicolumn{4}{|c|}{ Sex } \\
\hline Male & $18(42.9)$ & $24(57.1)$ & \multirow{2}{*}{0.504} \\
\hline Female & $26(44.8)$ & $32(55.2)$ & \\
\hline \multicolumn{4}{|c|}{ Age } \\
\hline $20-30$ yrs. & $0(0.0)$ & $3(100.0)$ & \multirow{4}{*}{0.252} \\
\hline $30-40$ yrs. & $3(27.3)$ & $8(72.7)$ & \\
\hline $40-50$ yrs. & $15(46.9)$ & $17(53.1)$ & \\
\hline$>50$ yrs. & $26(48.1)$ & $28(51.9)$ & \\
\hline \multicolumn{4}{|c|}{ Literacy } \\
\hline Illiterate & $1(100.0)$ & $0(0.0)$ & \multirow{4}{*}{0.055} \\
\hline Under Matric & $10(27.8)$ & $26(72.2)$ & \\
\hline Higher Secondary & $11(45.8)$ & $13(54.2)$ & \\
\hline Graduate and Above & $22(56.4)$ & $17(43.6)$ & \\
\hline \multicolumn{4}{|c|}{ Occupation } \\
\hline Govt. Employee & $5(26.3)$ & $14(73.7)$ & \multirow{3}{*}{0.143} \\
\hline Unemployed & $17(54.8)$ & $14(45.2)$ & \\
\hline Homemaker & $22(44.0)$ & $28(56.0$ & \\
\hline \multicolumn{4}{|c|}{ Family Income (Rs.) } \\
\hline$\leq 5000 /-$ & $9(49.0)$ & $13(59.1)$ & \multirow{5}{*}{0.078} \\
\hline $5000-10000 /-$ & $18(56.3)$ & $14(43.8)$ & \\
\hline $10000-15000 /-$ & $4(50.0)$ & $4(50.0)$ & \\
\hline $15000-20000 /-$ & $1(8.3)$ & $11(91.7)$ & \\
\hline$>20000$ & $12(46.2)$ & $14(53.8)$ & \\
\hline \multicolumn{4}{|c|}{ Religion } \\
\hline Hindu & $38(40.4)$ & $56(59.6)$ & \multirow{3}{*}{0.017} \\
\hline Muslim & $5(100.0)$ & $0(0.0)$ & \\
\hline Christian & $1(100.0)$ & $0(0.0)$ & \\
\hline \multicolumn{4}{|c|}{ Caste } \\
\hline General & $39(46.4)$ & $45(53.6)$ & \multirow{3}{*}{0.511} \\
\hline SC & $4(33.3)$ & $8(66.7)$ & \\
\hline ST & $1(25.0)$ & $3(75.0)$ & \\
\hline
\end{tabular}

\section{DISCUSSION}

This study was conducted in a tertiary care hospital of Agartala city among 100 diabetics attending outpatient department. The harmful effects that usually occur from complications of DM2 in affected patients make it difficult for healthcare providers for ensuring adequate blood sugar control to reduce or prevent associated morbidity and mortality. Inadequate treatment leading to uncontrolled blood sugar level, which is the manifestation of diabetes results in complications such as neuropathy, nephropathy, retinopathy and cardiovascular diseases. Important factors that contributed to achieving blood sugar control are adequate anti-diabetic medications as well as adherence to medication.

The present study has showed that majority of the patients visiting the clinic with cases of DM2 were female. A study from Nigeria reported that females were more compared to male.(14) In the present study, $56.0 \%$ were nonadherent to treatment. Imran $\mathrm{M}$ et al reported that $61 \%$ were non-adherent with medication; $18 \%$ and $21 \%$ of patients were moderately adherent and adherent to treatment respectively. Among non-adherent patients, males were more compared to females $(\mathrm{p}<0.05)$. Non-adherence was more among employed patients compared to unemployed patients ( $p$ > 0.05).(15) According to a study carried out by Mojtaba et 
al, $18.7 \%$ of patients were unable to adhere to their prescription medications.(16) Kavitha $S$ et al reported that the overall prevalence of non-adherence among respondents was $30 \%$. More than fifty percent of patients with smoking and alcoholic habits were not adherent to anti-diabetic treatment. Other reasons contributing to non-adherence to treatment were forgetfulness, inadequate knowledge about side effects, unhappy clinical visits and lack of assistance.(17) A study from Nigeria reported that their drugs as being unaffordable with the majority of them being women.(14) In the present study, half of the participants among the study subjects were female and unemployed. Almost similar findings were reported from Nigeria that women within the locality of the study area were largely unemployed. Therefore, the possibility of nonadherence to medications since those patients could not afford most of their medications. Also, the vast majority of patients visiting the clinics stated that they bought their drugs in bits due to high cost. This, however, could warrant missed doses when the medications were not obtained early enough. There was also the possibility of sub-optimal drug therapy as a result of brand differences since the medications could be obtained from differing sources with unguaranteed bioequivalence.(14) In the present study $63.0 \%$ were educated beyond secondary level and overall $99.0 \%$ were literate. Though, the level of education was quite high but did not show any significant relationship with treatment adherence ( $p>0.05$ ). There were $91.7 \%$ of the patient's family income that ranged from Rs. 15,000/- to 20,000/- were non-adherent to treatment. It was contradictory to the general conventional thought that higher income groups of people were more nonadherent compared to lower income group. A study from Nigeria(14) reported that about $85.5 \%$ of the patients have no education beyond secondary school and $56.6 \%$ of patients were 61 years and above. The possibility of obtaining employment that will ensure substantial income with such qualifications was low. The implication of the lower income was the probable inability to sustain the cost of medications for a chronic ailment like type 2 diabetes mellitus. However, besides the possible implication on affordability, there was no significant relationship between educational level and adherence.(14) In the present study, $48.0 \%$ patients were $>50$ years of age as comparable to a study conducted in Nigeria.(14) According to some studies,(18,19) significant relationship between ages of patients and their adherence to medication. In the present study, adherence was slightly higher in female than males ( $p>0.05)$. A study from Egypt showed that only $38.9 \%$ patients were belonging to the good category of adherence to medication. The non-significant higher rate of medication was found in females than in males.(20) It was comparable with the present study. Some studies reported that patients who had no insurance cover(21) or who had low income(22) were more likely to be nonadherent to treatment. It has been reported that in general, diabetic patients were non-adherent to their treatment and only a small number of diabetic patients were found adherent or compliant with all aspects of diabetic care.(23) In the present study, the lower educational level patients were more non-adherent compared to others ( $p>0.05)$. A similar result was reported by Kurtz et al that educated people tend to appreciate and understand the consequences of nonadherence. Thus, the degree of adherence was increased, but none significantly with increasing level of education.(24)
Mesfin $\mathrm{Y}$ et al reported that reasons for non-adherence were identified as forgetfulness, lack of patient education, financial problem or cost of medication, lack of patient provider relationship, shortage or availability problem, health facility being far or accessibility problem, problem in dosage form, feeling healthy without medication, afraid of addiction and being afraid of side effect.(25) Illiterate patients could not read or distinguish their medications, which increase the risk of errors and non-adherence. Illiteracy might negatively affect patient's medical knowledge.(26)

\section{CONCLUSION}

The overall adherence was $44 \%$ suggesting poor adherence among the diabetes patients. Females were more adherent compared to male ( $p>0.05$ ). The level of education was directly proportional to the treatment adherence $(p>0.05)$. No significant relationships were observed between sex, literacy, income, occupation and caste with treatment adherence.

\section{Strength and Limitation}

There was no known similar study conducted earlier in this population group. The study setup was accessible mainly by urban population. We cannot generalise the present study due to small sample size and limited to hospital only.

\section{Recommendation}

We recommend further study involving more subjects including rural and urban population. Health awareness activities may be carried out more vigorously throughout the state to cover all population groups.

\section{ACKNOWLEDGEMENT}

We are thankful to all participants without whom this would not have been possible.

\section{REFERENCES}

[1] Ogbera AO, Kuku SF. Insulin use, prescription patterns, regimens and costs - a narrative from a developing country. Diabetology \& Metabolic Syndrome 2012;4(1):50.

[2] Wild S, Roglic G, Green A, et al. Global prevalence of diabetes: estimates for the year 2000 and projections for 2030. Diabetes Care 2004;27(5):1047-53.

[3] Lindagren CM, Hirschhorn JN. The genetics of type II DM. Endocrinologist 2001;11:178-87.

[4] Anjana RM, Deepa M, Pradeepa R, et al. Prevalence of diabetes and pre-diabetes in 15 states of India: results from the ICMR-INDIAB population-based crosssectional study. Lancet Diabetes Endocrinol 2017;5(8):585-96.

[5] Murray CJL, Lopez AD. Alternative projections of mortality and disability by cause 1990-2020: Global burden of disease study. The Lancet 1997;349(9064):1498-504.

[6] Shaw JE, Sicree RA, Zimmet PZ. Global estimates of the prevalence of diabetes for 2010 and 2030. Diabetes Res Clin Pract 2010;87(1):4-14.

[7] Inzucchi SE. Diabetes Facts and Guidelines. 14th edn. Yale Diabetes Center: Takeda 2011. 
[8] Rozenfeld Y, Hunt JS, Plauschinat C, et al. Oral antidiabetic medication adherence and glycemic control in managed care. Am J Manag Care 2008;14(2):71-5.

[9] Ho PM, Rumsfeld JS, Masoudi FA, et al. Effect of medication non-adherence on hospitalization and mortality among patients with diabetes mellitus. Arch Intern Med 2006;166(17):1836-41.

[10] World Health Organization. Adherence to long term therapies: evidence for action. WHO, Geneva, Switzerland 2003.

[11] Lau DT, Nau DP. Oral antihyperglycemic medication non-adherence and subsequent hospitalization among individuals with type 2 diabetes. Diabetes Care 2004;27(9):2149-53.

[12] Sokol MC, McGuigan KA, Verbrugge RR, et al. Impact of medication adherence on hospitalization risk and healthcare cost. Med Care 2005;43(6):521-30.

[13] Census India 2011. http://northeasttourism.gov.in/agartala.html\#sthash. pwlYAUzR.dpbs. Accessed on 12/11/2018.

[14] Awodele 0, Osuolale JA. Medication adherence in type 2 diabetes patients: study of patients in Alimosho General Hospital, Igando, Lagos, Nigeria. African Health Sciences 2015;15(2):513-22.

[15] Imran M, Plathottam JJ. A study on treatment adherence among patients with type 2 diabetes mellitus attending diabetic clinic. Int J Community Med Public Health 2017;4(5):1701-3. http://www.ijcmph.com.

[16] Mojtabai R, Olfson M. Medication costs, adherence and health outcomes among medicare beneficiaries. Health Aff (Millwood) 2003;22(4):220-9.

[17] Kavitha S, Nalini GK, Suresh RM, et al. Treatment adherence and factors contributing to non-adherence among type 2 diabetes mellitus patients in a tertiary care hospital: a cross sectional study. Int J Basic Clin Pharmacol 2017;6(3):689-94.
[18] Sackett DL, Snow JC. The magnitude of compliance and non-compliance. In: Haynes NRB, Taylor DW, Sackett DL. eds. Compliance in health care. Baltimore: John Hopkins University Press 1979: p. 11-22.

[19] Dunbar J. Issues in assessment. In: Cohen NSJ. edr. New directions in patient compliance. New York: Lexington Books 1979: p. 41-57.

[20] Shams MEE, Barakat EAME. Measuring the rate of therapeutic adherence among outpatients with T2DM in Egypt. Saudi Pharmaceutical Journal 2010;18(4):225-32.

[21] Kaplan RC, Bhalodkar NC, Brown EJ, et al. Race, ethnicity and socio-cultural characteristics predict noncompliance with lipid lowering medications. Prev Med 2004;39(6):1249-55.

[22] Choi-Kwon, S, Kwon SU, Kim JS. Compliance with risk factor modification: early-onset versus late-onset stroke patients. Eur Neurol 2005;54(4):204-11.

[23] EI-Hadiyah TM, Madani AM, Abdelrahim HM, et al. Factors affecting medication non adherence in type 2 Sudanese diabetic patients. Pharmacology \& Pharmacy 2016;7:141-6.

[24] Kurtz SMS. Adherence to diabetic regimens: empirical status and clinical applications. Diabetes Educ 1990;16(1):50-9.

[25] Mesfin Y, Assegid S, Beshir M. Medication adherence among type 2 diabetes ambulatory patients in Zewditu Memorial Hospital, Addis Ababa, Ethiopia. Epidemiology (Sunnyvale) 2017;7(5):1-12.

[26] Sweileh W, Aker 0, Hamooz S. Rate of compliance among patients with diabetes mellitus and hypertension. An-Najah Univ J 2005;19:2-11. 